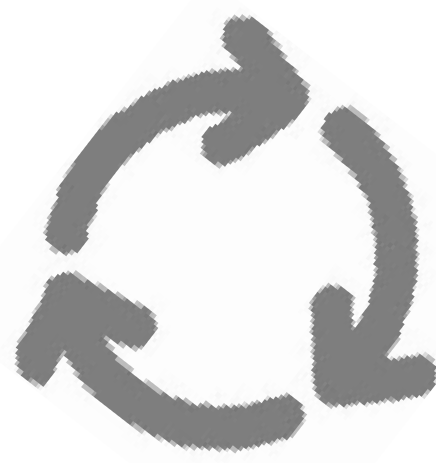

\title{
A constância da oralidade no desenvolvimento da comunicação humana e organizacional e em suas formas de comunicar
}

The frequency of the orality in the development of communication human being and organizacional and in its forms to communicate

Waldyr Gutierrez Fortes

Professor de Comunicação da Universidade Estadual de Londrina/PR

E-mail:wgfortes@londrina.net

Marta Terezinha Motta Campos Martins

Professora de Comunicação da Universidade Estadual de Londrina/PR

E-mail: martins@sercomtel.com.br

Participantes Discentes

Aline Cristine dos Santos

Beatriz Alves Marra

Fabiana Duarte Gomes

Juliana da Silva Kudo

Juliana Priscila Sussai

Juliano Augusto de Melo

Ramon Fernandes Louren-

Resumo

Apresenta a contribuição de alguns autores para a questão da comunicação humana e a comunicação oral que deve haver nas organizações modernas. Analisa que quanto mais a organização se moderniza, ficando em dia com as mais novas tendências tecnológicas e de mercado, mais precisa da comunicação oral para atingir seus objetivos. A oralidade precisa e deve ser resgatada para ocupar o seu lugar no planejamento de comunicação que deve haver nas organizações.

Palavras-chave: Comunicação Humana; Comunicação Oral; Oralidade; Organização; Imagem; Planejamento; Relacionamentos.

A evolução da comunicação

Segundo Santaella (2004), existem seis "Eras Culturais": a cultura oral, a cultura escrita, a cultura de impressão, a cultura de massa, a cultura midiática e a cibercultura. Em cada uma das eras existe a predominância de uma tecnologia comunicativa que provoca mudanças de processos e relações sociais. Dessa forma, muito da cultura de cada época está diretamente associada às tecnologias dos processos comunicativos que estavam ao alcance dos homens em determinado momento histórico.

No entanto, a mudança de uma era para a seguinte não implica o fim da outra. Elas coexistem, ou seja, independentemente da tecnologia de que dispomos, ainda fazemos usos de outras formas culturais.

Durante a era da Cultura Oral, o homem diferenciou-se de outros animais ao fazer uso de processos mais complexos de comunicação, transmitindo conhecimentos por meio da fala. Os conhecimentos transmitidos pela oralidade se fundamentavam em experiências adquiridas, e desde a Grécia Antiga a retórica era alvo de estudo de filósofos. Apesar do avanço proporcionado à comunicação humana, a oralidade apresenta restrições em relação à disseminação de conhecimentos, como afirma Lévy (2001, p. 114).

Nas sociedades orais, as mensagens lingüísticas eram recebidas no tempo e lugar em que eram emitidas. Emissores e receptores compartilhavam uma situação 
idêntica e, na maior parte do tempo, um universo semelhante de significação. Os atores da comunicação evoluíam no mesmo universo semântico, no mesmo contexto, no mesmo fluxo vivo de interações.

Ainda assim, pode-se dizer que a cultura oral possibilitou tantos avanços na maneira de se comunicar que continua sendo utilizada até hoje, graças à evolução dos meios comunicativos e das tecnologias da oralidade, que aprimoraram e superaram algumas limitações encontradas.

Já na Cultura Escrita, a memória torna-se externa ao indivíduo, fazendo com que a memorização fique em segundo plano, e a habilidade de interpretar, de registrar o ocorrido se torne possível. Nesse período, o conhecimento é repassado de forma mais centrada e objetiva, e a transmissão de idéias não depende mais da fala e da oralidade para se perpetuar. A escrita possibilitou a comunicação entre pessoas de diferentes épocas, que poderiam nunca ter tido contato real.

A Cultura de Impressão, seqüencialmente à Escrita, traz possibilidade de organizar conheci-mentos e divulgá-los em grande escala, resultando no desenvolvi-mento da literatura popular e da ciência e da história modernas e na elevação de Estados a nações.

A imprensa fez surgir as maiores mudanças na cultura do homem desde a invenção do alfabeto, uma vez que permitiu a liberdade de pensamento, devido à interpretação pessoal de cada um, e não mais as pressões e influências sociais de outros grupos dos quais adquiriam conhecimento.

A ilusão inicial, que acreditava no acesso de toda a sociedade ao conhecimento, foi barrada pelo analfabetismo. Além disso, os veículos de comunicação passaram a ser utilizados para fins políticos totalitários, como o nazi-fascismo e o stalinismo. Com o capitalismo, a massificação das mensagens dá início à indústria cultural e, em conseqüência, à cultura de massas.

Essa Cultura é conseqüência da revolução da comunicação, paralelamente à Revolução Industrial. Com importantes mudanças nos processos comunicativos no Século XX, a produção sistemática e em grande quantidade cria a cultura de massa e o consumismo. Nesse momento, a comunicação tem um caráter cosmopolita, "vende" sonhos e ilusões, dando surgimento a uma sociedade que cria mitos e que transforma o consumo em um consolo para a vida que os indivíduos criam em suas imaginações.

Bastante complexa, a cultura de massa é contraditória, uma vez que essa sociedade é marcada pela fusão de diferentes elementos culturais. Dessa forma, a comunicação busca atingir os pontos em comum e os veículos mais abrangentes se resumem à televisão.

Esse novo paradigma tecnológico resultou em mudanças profundas nas relações culturais da sociedade.

Daí surge a Cultura das Mídias, que representa o início da introdução de elementos interativos na comunicação, que acabaram por modificar a cultura da sociedade, graças à introdução de novas formas de relacionamentos entre os indivíduos e as tecnologias.

Esse período marca os primeiros passos da comunicação e da cultura informatizadas e interativas. O uso dos meios de comunicação de massa se faz presente e se mistura aos avanços das tecnologias, gerando uma nova realidade de comunicação, baseada na interatividade.

Por fim, a era da Cibercultura traz as novas tecnologias, que per- 
mitem a criação de uma interface diferente com a realidade, transformando a relação dos indivíduos com o mundo. Sem definições limitadas - reflete um momento não findado - tem sua característica principal no novo posicionamento dos indivíduos perante os processos comunicativos. As transformações sociais e tecnológicas resultam na desmassificação, isto é, na pluralização das visões de mundo e dos novos posicionamentos e anseios da sociedade em relação ao todo.

A comunicação no contexto organizacional

Ao mesmo passo em que a cultura comunicacional da sociedade foi se modificando e aprimorando de acordo com a evolução do próprio homem, assim também se deu no contexto organizacional. A necessidade de acompanhar os anseios de consumi-dores e da própria opinião pública fez com que as corporações desenvol-vessem sistemas de comunicação voltados para a melhoria de suas relações internas e externas, no sentido de valorizar a influência da sociedade no desenvolvimento de seus negócios.

Assim, a construção de corporações sólidas, hoje, depende não apenas dos produtos e serviços oferecidos, mas também da gestão do relacionamento e da comunicação com os grupos de interesse.

Existem diversas ferramentas de comunicação que contribuem para o desenvolvimento da imagem das organizações, especialmente quando se sabe a quem dirigir os esforços (públicos de interesse) e como. No entanto, há como edificar um eficiente diálogo com os públicos a partir de uma "ferramenta" genuinamente humana, simples, que necessita ser organizada, ajustada e vista como estratégica: a comunicação oral.
0 potencial da comunicação oral

A fala é um ingrediente básico no processo de socialização e um poderoso meio de reação ou revelação da personalidade. Por intermédio dela é possível estimular e controlar aquele com quem se está comunicando, bastando apenas que haja um esforço de estabelecer relacionamento por uma das partes.

Havendo o esforço de estabelecer relacionamento, é necessário encontrar o melhor meio para desenvolver a mensagem. Cabe, então, identificar o foco de interesse, de acordo com as necessidades do "ouvinte"; ajustar a mensagem às condições desse ouvinte, de forma a estimular uma resposta; organizar a mensagem, sempre equilibrando originalidade e redundância; e desenvolver uma linguagem clara, concisa e coerente.

Tal cuidado com a oralidade deve ocorrer com a preocupação de que as pessoas agem na informação, ou seja, recebem indícios para modificar ou aperfeiçoar seu comportamento quando se comunicam.

Além da facilidade de influenciar o comportamento, mediante a adequação da mensagem, na comunicação oral, os gestos, o corpo, o semblante dos emissores também emitem mensagens quando estão se comunicando. A linguagem, a precisão e a espontaneidade utilizadas nas explanações e diálogos influenciam diretamente a apreensão de informações.

Ainda, a oralidade é um ato de resposta em dois sentidos: responde-se por ela e por meio dela revelam-se pensamentos interiores e emoções. E é a união de todas essas características peculiares que demonstra o resultado de um estímulo do relacionamento estabelecido ou que vai contribuir com esse resultado 
perante o ouvinte.

Assim, podemos dizer que a comunicação oral, a partir de seu potencial estimulador, por meio da adequação da linguagem e da entonação, tem grande importância estratégica no processo de comunicação das organizações. A comunicação oral permite a readequação enquanto está se processando e ser remodelada durante sua execução, abrindo-se espaços para a melhor condução diante das necessidades e exigências do emissor ou receptor.

Planejamento da oralidade nas organizações

O planejamento da comunicação organizacional com seus diversos públicos é a base para a construção de um bom relacionamento. Sua importância é clara, pois "a falta de uma linguagem única que percorra toda a empresa [...] traz obstáculos naturais que impedem a cooperação e a troca de informações entre os diversos públicos" (Fortes, p. 217).

Entendendo-a como um meio de comunicação, é necessário ponderar sobre questões como: quais os públicos de interesse? Quais os melhores meios de comunicação para atingir cada público? Qual o custo e o resultado esperado?

Normalmente, no processo de planejamento das comunicações da organização, busca-se responder a estas e outras perguntas, definindo estratégias específicas para cada público. Entre essas estratégias estão os veículos utilizados para a divulgação da mensagem, possibilitando um processo de comunicação público-empresa. Inserido nesse planejamento, a oralidade, muitas vezes, não é tratada com sua devida importância, ficando presa na informalidade. Planejar a oralidade impede que esta assuma um caráter de improviso, dando possibilidade para seu uso estratégico.

A oralidade é a forma de comunicação mais antiga e a mais comum, e, talvez por isso, não receba especial atenção quanto ao planeja-mento. Jackson e Bland defendem que a comunicação oral é a mais antiga e a melhor forma de comunicação, devendo ser encarada com sua devida importância. "[...] conferências, reuniões e discursos precisam tanto ser estruturados como uma projeção de slides ou o lançamento dos jornais da empresa" (1990, p. 93).

Com isso, é possível perceber o potencial estratégico que a oralidade pode assumir, pois, mais do que qualquer outra forma de comunicação, a comunicação oral tem maior riqueza de detalhes, possibilita uma resposta imediata e facilita o contato direto. Por isso, ela deve ser planejada e trabalhada com estra-tégias, como os outros veículos, "afinal, mesmo os modernos meios de comunicação não são mais do que formas sofisticadas de oralidade" (Fortes, p. 285).

Algumas práticas de uso da oralidade são muito comuns nas organizações e têm extrema importância no desenvolvimento de seus relacionamentos. A saber:

\section{Conferênicia na adminsitração}

A conferência é um método de comunicação formal e horizontal. Seu valor está em permitir a transmissão da mensagem com rapidez, e seus tópicos podem ser examinados em profundidade, sem perturbação das partes e da partici-pação direta dos ouvintes, pois durante sua realização não se admitem debates.

A principal utilização do processo de conferência na administração tem sido como técnica de treinamento. $\mathrm{O}$ incentivo a conferências entre a administração e os funcionários tem como finalidade levantar o moral, 
reduzir as ausências e movimentos de classe, fortalecer a supervisão e aumentar o fluxo de sugestões. Santos $(1979$, p. 146) afirma que

[...] o intercâmbio oral que tem lugar em uma conferência aumenta a compreensão e a aceitação em casos em que o resultado não poderia ser obtido de outra forma. O elemento essencial é a integração que se processa tanto entre os indivíduos que dela participam, quanto entre indivíduos e os grupos.

Reunião

Seu objetivo é possibilitar que as pessoas especializadas trabalhem em equipe, com um sentido de finalidade comum e coorporativa. Diferentemente da conferência, a reunião permite que os participantes interajam entre si para propor novas idéias; neste caso, a reunião torna-se uma via de mão dupla que permite ao comunicador receber informações e repassá-las novamente.

Treinamento

Treinamento é um processo de assimilação cultural a curto prazo, que busca repassar ou renovar conhecimentos, habilidades ou atividades relacionadas diretamente à execução de tarefas ou à sua otimização no trabalho.

A importância da comunicação entre instrutor e treinando está nas relações interpessoais e envolve o universo que lhes permite criar um relacionamento. No treinamento, a comunicação se dá na transmissão de idéias, conceitos e habilidades aos treinandos, visando comunicar métodos e técnicas de trabalho para atingir objetivos pré-estabelecidos.

No entanto, em meio a esse intercâmbio de informações podem surgir ruídos, tais como:
Ausência de clareza e objetividade.

> Excesso de informações. Falta de controle dos resultados

$>$ da comunicação.

$>$ Métodos e técnicas inadequados.

$>$ Confusão quanto ao sentido

$>$ de certas expressões e pensa-mentos expostos pelo instrutor.

> Despreparo do treinando para receber determinada comunicação.

> Mensagens longas e sem conteúdo.

Para evitar esses ruídos, o instrutor precisa planejar sua exposição, levantando questiona-mentos que o direcionem de acordo com as expectativas dos treinandos; ter em mente a clareza das idéias antes de comunicar os propósitos, aspectos físicos e humanos; ter conteúdo e controle, a fim de que possa facilitar a comunicação.

\section{Media training}

Nogueira (2007, p. 25) defende como ponto principal que, devido à "crescente importância da boa governança corporativa para uma imagem favorável da empresa", as questões comunicacionais e a "abertura da companhia a fim de prestar esclarecimentos solicitados pela imprensa são de grande valia para demonstrar à opinião pública a transparência de sua gestão".

Possuir diferenciais é requisito indispensável à sobrevivência, permanência e/ou destaque das organizações no mercado globalizado de hoje. E, diante dessa nova dinâmica, várias são as "novas" ferramentas utilizadas pelas empresas para a conquista e maximização de pontos favoráveis que garantam atenção positiva por parte dos clientes, mídia 
e comunidade em geral.

Nesse contexto, o nível estratégico da comunicação auxilia as empresas na busca desses diferenciais, comunicação esta que é pensada em todas as dimensões: interna, externa, institucional e, certamente, também na vertente da oralidade, já que a maior parte da comunicação das organizações, e delas para com seus grupos de interesse, dá-se verbalmente.

Assim, nasce a preocupação com o preparo das informações a serem divulgadas e com o planejamento estratégico da oralidade no anúncio das mensagens organizacionais aos grupos de interesse, principalmente à mídia, já que esta, segundo Nogueira (2007, p. 22), influencia a opinião pública a respeito de uma empresa, seus produtos e serviços.

Então, é fundamental o planejamento da oralidade, no sentido de garantir que todos os envolvidos recebam informações corretas e concretas e, ainda, evitar que boatos e conflitos se instalem durante o processo de transmissão das mensagens.

Além disso, a preparação dos profissionais que se pronunciarão como porta-vozes da empresa tornase primordial, uma vez que, segundo Nogueira, "[...] nenhuma empresa tem voz própria. Elas só falam pelas bocas de seus executivos" (2007, p. 23).

É importante ressaltar que o posicionamento das empresas e dos executivos na questão da oralidade diante de situações de crise merece ainda maior cuidado, já que as emissões de informação realizadas por eles, nessas situações, e, conseqüentemente, divulgadas pela mídia, contribuirão para a formação de uma percepção favorável ou não da empresa, por parte da opinião pública.

Utchitel (2007, p.130) afirma que "é fundamental assegurar sem- pre a manutenção de um discurso único na empresa e a divulgação de informações de interesse corporativo. Toda essa sintonia exige treina-mento". Tal afirmação deve permear realmente a oralidade das organi-zações, qualquer que seja o momento que estejam vivendo.

Já Thielmann (2007, p.135) aborda a dinâmica da transmissão das informações pela televisão e comenta que "são sons e movimentos via satélite vencendo divisas, rompendo barreiras e levando a informação mundo afora em instantes". Assim, pela velocidade do processo, "não há como silenciar ou se distanciar perante a repercussão de certos fatos. Atualmente, mais do que nunca, a comunicação empresarial é o diferencial do mundo dos negócios."

Diante dessa afirmação, é claro que se pode evidenciar o cuidado indispensável à oralidade organizacional, já que a televisão tem grande poder de disseminação e influência nos mais variados grupos de interesse das organizações e é uma das bases responsáveis pelo fortalecimento das identidades corporativas.

Thielmann (2007, p.150) também afirma que "é indispensável que a informação da empresa seja uniforme. Igual para todos os setores". Em todas as unidades, filiais, departamentos da empresa, a informação deve ser veiculada e enfocada da mesma forma. Além disso, a capacidade de ouvir e receber informações dos que serão portavozes das organizações certamente se reflete também no processo de comunicação.

Portanto, a relevância do cuidado com o processo oral de comunicação fica evidente, pois a comunicação está diretamente ligada à construção e ao fortalecimento da identidade das organizações, que, por sua vez, se reflete na imagem e no posiciona- 
mento no mercado.

Ponderações importantes no planejamento

O planejamento da oralidade deve ser inserido no plano geral de comunicação, que tem por objetivo definir os públicos a serem trabalhados, formular estratégias para os meios de comunicação com os públicos, organizar os recursos técnicos e físicos dos programas de relacionamento, entre outros fatores.

Tendo como ferramenta a oralidade, é importante definir cuidadosamente os públicos que serão trabalhados. Definidos os públicos, é hora de formular estratégias e escolher os veículos de comunicação que serão utilizados, entre eles, conversas pessoais, reuniões, telefone, etc.

Para que a comunicação seja alcançada com eficiência, faz-se necessário, dependendo do veículo escolhido, observar certas características da comunicação oral, que compreendem a codificação da mensagem.

Para cada situação deverão ser explorados um ou mais aspectos da oralidade, incluindo outras formas de comunicação. Por exemplo, escolhendo reuniões ou visitas dirigidas como estratégia de relacionamento com determinado público, além de serem observados aspectos como recursos visuais ou audiovisuais que servirão de auxílio em alguma apresentação. O representante da organização deverá ter total controle de sua entonação de voz, pausas e movimentos corporais. Essas características contribuem para a eficácia da comunicação, tornando mais fácil a transmissão e compreensão da mensagem. Fica ainda mais fácil visualizar se, por exemplo, a organização adotar um sistema de teleatendimento, que tem a oralidade em si como única transmissora de informações.
Ao dar uma nova forma à oralidade na organização, faz-se necessário um treinamento com os representantes sobre o tema, considerando sua importância e a melhor forma de utilizá-la nas diversas situações. Com pessoas que desem-penham o papel de representar a organização em reuniões, coletivas de imprensa, ou qualquer outro ato que exija habilidades de oratória, há necessidade de ressaltar a importância da comunicação verbal e não-verbal.

Já no âmbito interno, a unificação do discurso é de suma importância, a fim de acabar com os ruídos. Neves (2000) demonstra esse cuidado ao tratar da gerência da comunicação simbólica, aumentando o controle sobre os inúmeros "emissores" que operam na organização, muitas vezes liberando mensagens na contramão das desejadas pela empresa. Seguindo esse exemplo, a oralidade deve ser vista de forma geral, pois cada integrante da empresa pode exercer papel de representação para algum público, influenciando sobre o conceito criado da empresa, divulgando uma imagem da organização.

Abstract

Presents some contributions from authors to the human being communication question and the oral communication that should have in modern organization. Makes a critical analysation, that, at the time the organizations get modern, up to date with the news technologies and market tendency, more it needs the oral communication to reach their aim. The orality needs and must be brought it back to rank foremost the communication planning that must have in the organizations.

keywords: Human Being Communication; Oral Communication; Orality; Organization; Image; Planning; Relationships.

Bibliografia

CARVALHO, Antônio V. Treinamento de recursos humanos. São Paulo: Pioneira, 1988.

FORTES, Waldyr Gutierrez. Relações Públicas: processo, função, tecnologia e estratégias. 2 . 
ed. São Paulo: Summus, 2003.

LÉVY, Pierre. Cibercultura. 2. ed. São Paulo: Editora 34, 2001.

MARRAS, Jean Pierre. Administração de recursos humanos: do operacional ao estratégico. 3. ed. São Paulo: Futura, 2000.

PICCOLOTTO, Leslie; SOARES, Regina Maria Freire. Técnicas de impostação e comunicação oral. São Paulo: Summus, 1977.

SANT' ANNA, Flávia Maria. Microensino e as habilidades técnicas do professor. São Paulo: McGraw-Hill do Brasil, 1979.

SANTAELLA, Lúcia. Culturas e artes do póshumano: da cultura das mídias à cibercultura.
2. ed. São Paulo: Paulus, 2004.

SANTOS, Gelson Clemente dos. Comunicação administrativa. 2. ed. São Paulo: Gradus, 1979.

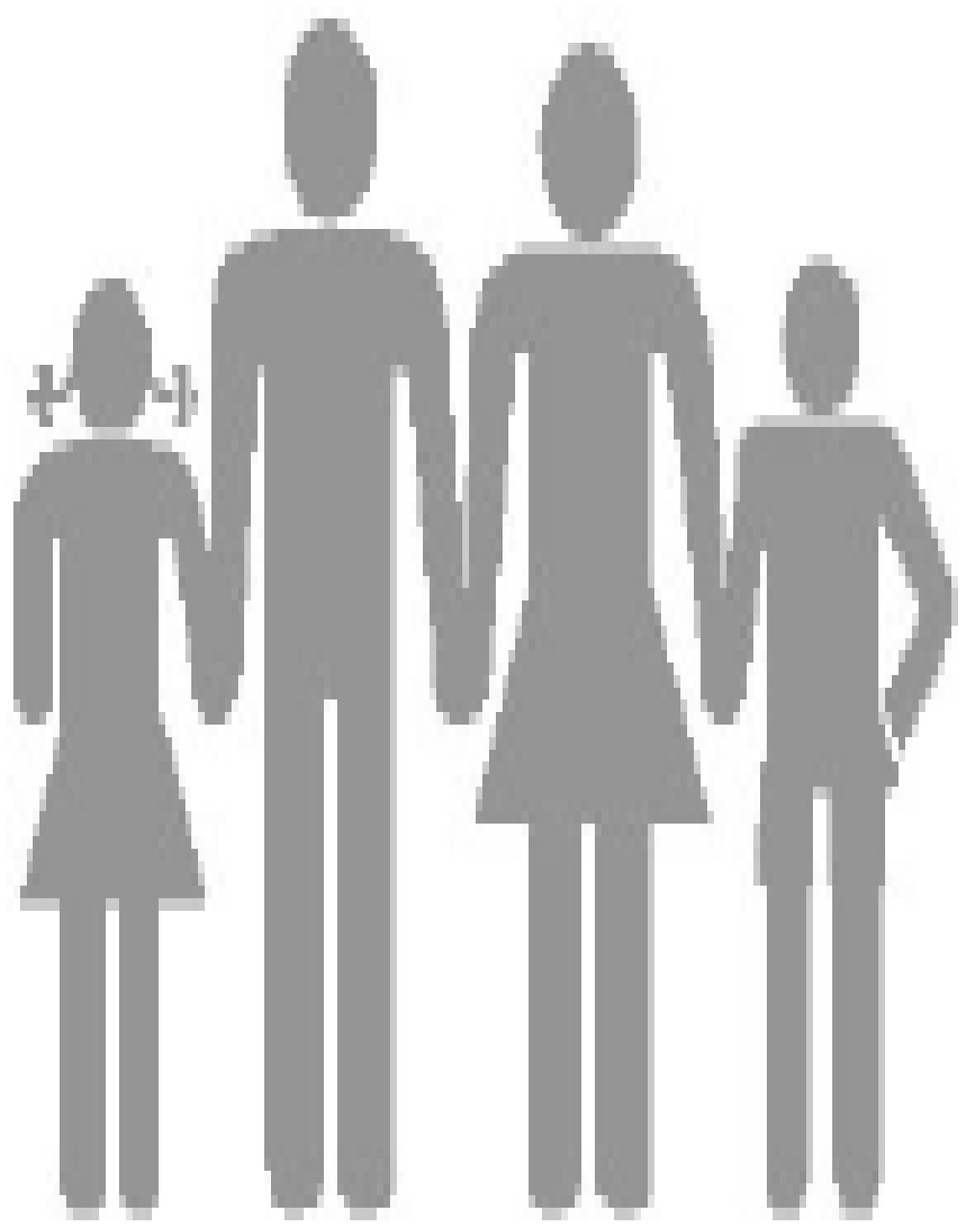

Data do recebimento: 15/05/2007

Data do aceite: 28/06/2007 